\title{
Study of the problem of agricultural industrialization leading enterprises in resource development and utilization based on the functional model
}

\author{
XIAO Li $^{1}$, LI Songqing ${ }^{1}$, LIU Yiling ${ }^{2}$ \\ ( ${ }^{1}$ Hunan Agricultural University Business School, Changsha, Hunan, China, 410128) \\ ( ${ }^{2}$ International College of Hunan Agricultural University, Changsha, Hunan, China, 410128) \\ E-mail:yiling8898@163.com
}

\begin{abstract}
. the reasonable use of agricultural resources and recycling is the basic requirement of construction of China's economic sustainable development, realize the effective use of agricultural enterprise resources has important significance not only in management theory, but also for the sustainable development of our country's economy has an important role in promoting. Based on functional model, this paper constructed the functional maximum model, calculated the optimal value of exploitation and utilization of agricultural resources, for our country agricultural industrialization leading enterprises in resources exploitation to provide guidance. Further, the article from the perspective of mathematical model, discusses the resource exploitation of quantitative model in practical application of the limitation of agricultural resources problems combined with the mathematical model can be effectively.
\end{abstract}

Key words: agricultural industrialization; agricultural resources; functional model

\section{Introduction}

Agricultural resources are the most basic that human in the survival and reproduction of material resources, at the same time, the agricultural resources is non-renewable or difficult to renewable resources. At present, more than $75 \%$ of the agricultural products and more than $85 \%$ of the energy supply from agriculture resources, our country land area accounted for $7.2 \%$ of the world's land area available, the third in the world rankings, and cultivated land area and garden area accounted for $7 \%$ of the area are available, and the world in the fourth, river runoff accounted for $5.6 \%$ of the world's river flow, in the fourth. However, due to the large population in our country, therefore, agricultural resources per capita are less, and resources common quality is not high. In arable land area, for example, China's arable land accounted for only $10 \%$ of land area, and were less arable land is still in years, so the reasonable utilization of agricultural resources, developing ecological economy, is to guarantee the sustainable development of agricultural economy and agricultural industrialization enterprises of our country's basic requirements. How to realize the reasonable development and effective utilization of the existing agricultural resources, is the most realistic problem, and agricultural industrialization enterprises inevitably in the operation and management of a problem, this article from the perspective of mathematical methods considering the development and utilization of agricultural resources optimal solutions, at the same time of using mathematical method applied to the development and utilization of agricultural resources problems puts forward some Suggestions. 


\section{Based Model}

Agricultural resources is difficult to regeneration, is the main reason why seek resources development and utilization optimal. Development and utilization of agricultural resources unchecked, can lead to tension and even exhausted resources, so in order to realize the sustainable development of economy, companies or government in the process of development and utilization of agricultural resources must carry out effective management and control. In the optimization process of resources development and utilization is discussed, should also consider the resources development and utilization of economy. In the current price level or established, to determine whether a resource for development, in order to realize the optimal economic efficiency of enterprises.

From the perspective of mathematical measurement and agricultural resource definitions, get the basic composition of agricultural resources economic structure factors include: agricultural resources reserves, agricultural resources price, basic agricultural resource extraction rate as well as the resources of mining cost. Optimal levels to explore the development and utilization of agricultural resources, also should consider the protection of environment and environmental sustainable development, therefore, should also join in the measurement of control variables, such as production rate, in under the condition of protecting the environment to achieve maximum economic benefits.

Building agricultural resources exploitation model is the basic idea of the differential equation and functional combination of variational method, on the basis of the equations are simplified, so as to build a functional model and the model of functional maximum value, to determine the optimal extraction rate of resources.
Model hypothesis: set up before assuming that agricultural resources recovery $\mathrm{f}(\mathrm{t}), \mathrm{x}(\mathrm{t})$ mining rate, agricultural resources price $p(t)$ are time dependent functions; Without considering the special policy and government tax, total revenue will only be affected by the resource price and currency in the discount rate, and in this model, without considering due to special reasons such as natural disasters on economic losses as well as the potential impact on prices.

To solve the above model: suppose $f=f(t)$ at time $t, a$ agriculture area agriculture resources recovery, and its initial value is set to $f(0)$, and $f(0)>0$. So, rate of mining in the known conditions for a time dependent function, can be set up as shown in formula (1) the cauchy problem of:

$$
\left\{\begin{array}{c}
\frac{d f}{d t}=-x(t) \\
f(0)=R
\end{array}\right.
$$

Hypothesis in the production function, when $\mathrm{t}=\mathrm{t} 1$, agricultural resources drying up, at this time $\mathrm{f}(\mathrm{t} 1)=0$,assuming maximum recovery rate in the model for xmax, then the equations of simplified mathematical model of agricultural resources recovery.

Assumption in the market, the agricultural resources of the purchase price for $p$ and $p=p$ $(\mathrm{t})$, and assuming that $\mathrm{p}=\mathrm{p}(\mathrm{t})$ is known, the owner of the resource target is the use of the resources, realizing the maximization of profit, assumes that the currency in the discount rate for $\delta$ 且 $\delta>0$, then at $\mathrm{t}$ time gains $\mathrm{k}=\mathrm{k}(\mathrm{t})$ is also meet the cauchy problem, as shown in formula (2) :

$$
\left\{\begin{array}{l}
\frac{d k}{d t}=\delta k \\
k(0)=k_{0}
\end{array}\right.
$$

$\mathrm{k} 0$ said funds, to solve formula (2) can get $\mathrm{k}=\mathrm{k}_{0} \mathrm{e}^{\delta}$, therefore present value $\mathrm{k}_{0}=\mathrm{e}^{-\delta} \mathrm{k}(\mathrm{t})$, therefore, to the mining problem, total Present value formula $\mathrm{K}_{1}$ shall be:

$$
K_{1}=\int_{0}^{\infty} e^{-\delta} p(t) x(t) d t
$$




\section{Model Results}

In order to obtain the maximum, constructs the Hamiltonian function:

$$
H_{1}=e^{-\delta} p(t) x(t)=\lambda(t) x(t)
$$

The $\lambda(t)$ as the adjoint variable.

According to the functional change of the maximum principle, satisfied contain adjoint variable equation of optimal solution:

$$
\frac{d \lambda}{d t}=-\frac{\partial H_{1}}{\partial x}=0
$$

Formula $\lambda=$ const can be calculated by the (5) , which is suitable for constant, $H_{t_{1}}=\left[e^{-\partial t} p\left(t_{1}\right)-\lambda\right] q\left(t_{1}\right)$.

In order to achieve maximum of $\mathrm{H} 1, \mathrm{q}$ shall be:

$$
q=\left\{\begin{array}{c}
0, p(t)<\lambda e^{-\partial\left(t-t_{1}\right)} p\left(t_{1}\right) \\
q \max , p(t) \geq \lambda e^{-\partial\left(t-t_{1}\right)} p\left(t_{1}\right)
\end{array}\right.
$$

To get the best of $\mathrm{H} 1$ resources exploitation control scheme, which reflect the market price of the agricultural resources and agricultural production rate are highly mathematical relations. When in the market, the price of agricultural resources is not lower than the enterprises the best extraction rate is the biggest mining resources rate qmax, agricultural resources and when the market price is lower than enterprise shall stop mining. In theory, according to the analysis results, to achieve the optimal result of resources exploitation, both to is beneficial to the sustainable development of agricultural resources, guaranteed the agricultural enterprise profit maximization, at the same time also can meet the market demand for agricultural resources.

\section{Model Optimization}

In this paper the model is a simplified version of the model, to consider from the Angle of agricultural industrialization, also can add more controllable factors. In the model, for example, to join the agricultural resources of mining cost, namely considering production cost under the condition of the optimal control, assume that the resources of a positive ratio relationship mining cost and production rate, so the total present value will be:

$$
K_{2}=\int^{\infty} e^{-\partial t}[p(t) q(t)-c(\mathrm{q}(\mathrm{t}), \mathrm{t})] d t
$$

Accordingly, the Hamiltonian model will be:

$$
H_{2}=\left[e^{-\partial t} p(t)-\lambda(t)\right] q(t)-e^{-\partial t} c(q(t), t) \text { Ac }
$$

cording to a maximum of functional variational method, can get:

$$
\frac{\partial c}{\partial q}=p(t)-\lambda e^{\partial t}
$$

Put this result as a fixed value, and analyzed by using the method of coordinate system drawing, can be found that the curve $\mathrm{y}=\mathrm{c}(\mathrm{q}, \mathrm{t})$ and the curves $\frac{\partial c}{\partial q}=p(t)-\lambda e^{\partial t}$ intersect, resource optimal extraction rate $\mathrm{q}$ y has a value of curve $\frac{\partial c}{\partial q}=p(t)-\lambda e^{\partial t}$ in the slope for the abscissa, the rest of the cases, mining rate $\mathrm{q}$ value is 0 .

\section{Results Analysis}

The mathematical model built using generic function to get the biggest benefit is the purpose of the total present value, through the Hamiltonian function and the adjoint equation, when the guide function under the condition of zero and get the most value, the optimal control of resource extraction rate can be obtained.

As demand for big difficult to renewable resources, the principles of sustainable development is the development of agricultural resources must abide by the principles. To construct the mathematical model can pass number, said only when the price reaches a 
certain level of agricultural products, agricultural leading enterprises to mining, according to a certain number so as to realize the maximization of the benefits of enterprises, and when the price of agricultural products is lower than those at ordinary times, enterprises shall timely stop drilling, in order to achieve the purpose of protecting resources.

The analysis using the model, will need to set a series of assumptions, the premise of the model and these assumptions often cannot satisfy the reality conditions of special circumstances. Although this is a more special conditions, were less likely to occur and have less effect on the resources integrity, but when the data is bigger or operation number is large, neglected factors can cause interference to a certain extent, the mathematical model, which affect the accuracy of the results.

When using mathematical model to calculate, inevitably produce certain error, despite the error may be small, but the error are also important factors influencing the accuracy of the analysis results. In theory, using the numerical model of the algorithm was improved, the model can effectively reduce the error, but from actually said, have no way to eliminate the error caused by the model is.

Experts to model of subjectivity is the index of agricultural resource development professional degree, hypothesis of subjective judgment of some factors such as factors, these factors for the model and the analysis of the results will have important influence, therefore, the application mathematical model for the analysis of agricultural leading enterprises in resources exploitation utilization of there are still some limitations.

\section{References}

[1] Wang Leci. using the functional model solve the problem of the development and utilization of mineral resources [J]. China Mining Magazine, 2015.5:46-48

[2] Cui Chunsheng. A combined recommendation algorithm based on functional network [J]. System Engineering Theory and Practice, 2014,04: 1034-1042.

[3] Dong Jiangai, Zhang Yi. The way of agricultural modernization of resource-based county enterprises: a case study of Shanxi Xiangning County typical investigation and reflection[J]. Journal of Wuhan University (PHILOSOPHY AND SOCIAL SCIENCES EDITION), 2013,05:29-34.

[4] Qian Mingjie, Wu Jing, Lv Huiling. The exploitation of resources in arable land abandonment phenomenon -Taking Zhidan County of Shaanxi Province as an example [J]. Resource Development \& Market, 2013,11:1182 $-1184,1136$ 